\title{
Greening offshore wind with the Smart Wind Chart evaluation tool
}

\author{
Takvor Soukissian ${ }^{1}$, Sofia Reizopoulou ${ }^{1}$, Paraskevi Drakopoulou ${ }^{1}$, Panagiotis Axaopoulos ${ }^{1}$, \\ Flora Karathanasi ${ }^{1,2}$, Simona Fraschetti ${ }^{3}$, Laura Bray ${ }^{1}$, Federica Foglini ${ }^{4}$, Anastasios Papadopoulos ${ }^{1}$, \\ Francesco De Leo ${ }^{3}$, Chara Kyriakidou ${ }^{1}$, Evangelos Voukouvalas ${ }^{5}$, Evangelos Papathanassiou ${ }^{1}$, and \\ Ferdinando Boero ${ }^{3,6}$ \\ ${ }^{1}$ Hellenic Centre for Marine Research, P.O. Box 712, 19013 Anavyssos, Greece \\ ${ }^{2}$ School of Naval Archit. \& Marine Eng., National Technical Univ. of Athens, Heroon Polytechneiou 15573, \\ Zografos, Athens, Greece \\ ${ }^{3}$ Dipartimento di Scienze e Tecnologie Biologiche ed Ambientali, Università del Salento, CoNISMa, \\ Via Prov.le Lecce Monteroni, 73100 Lecce, Italy \\ ${ }^{4}$ CNR-National Research Council of Italy, ISMAR-Marine Sciences Institute, via Gobetti 101, \\ 40129, Bologna, Italy \\ ${ }^{5}$ European Commission, Joint Research Centre (JRC), Institute for Environment and Sustainability, \\ Climate Risk Management Unit, Via Enrico Fermi 2749, 21027 Ispra (VA), Italy \\ ${ }^{6}$ Istituto di Scienze Marine del CNR, 16149, Genoa, Italy \\ Correspondence to: Takvor Soukissian (tsouki@hcmr.gr)
}

Received: 1 November 2015 - Revised: 18 February 2016 - Accepted: 25 February 2016 - Published: 9 March 2016

\begin{abstract}
The development of offshore wind farms (OWFs) and the establishment of marine protected areas (MPAs) comprise two main elements for the production of clean energy, and the simultaneous maintenance and protection of biodiversity in the Mediterranean and Black seas. Successful, efficient, and sustainable coupling of these two aspects presumes that the criteria for selecting suitable locations for the deployment of OWFs should not only include technical-engineering terms (e.g. high wind energy efficiency, bottom suitability, inland infrastructures) but also ecological-environmental considerations (e.g. the least possible impact on biodiversity, ecosystem functioning) and socio-economic aspects (e.g. effects on coastal and marine activities, development of marine spatial planning). In the context of the FP7 CoCoNet project, the integration between OWFs and MPAs is based on four main steps: (i) the identification of existing (networks of) MPAs focusing on the biodiversity distribution patterns and current legislation, (ii) the coupling of offshore wind potential within networks of MPAs, (iii) the evaluation of the knowledge gained up to date and the theoretical approaches at the two pilot sites of the Mediterranean and Black sea basins, and (iv) the development of the "Smart Wind Chart", a convenient and rational tool addressed to scientists and policy makers for the evaluation of maritime policy management schemes. The latter step comprises the core of this work.
\end{abstract}

\section{Introduction}

The exploitation of wind energy has long been recognized as a key element in the common EU energy policy in order to reduce the dependence on fossil fuel and emissions from carbon sources, to decouple energy costs from oil prices, and to ensure a secure energy supply. Although onshore wind energy generation is currently cheaper than offshore, finding new suitable onshore sites is becoming increasingly difficult in Europe. Offshore wind energy (OWE) is an attractive alternative solution to take advantage of marine winds, which tend to be higher, more frequent, and less variable than inland winds. Despite the tremendous development of offshore wind farms (OWFs) in the northern European countries, with more than half of the installed offshore capacity belonging to 
the UK, no full-scale OWFs have been developed yet in the Mediterranean and Black seas.

The development of OWFs in these two basins seems to be an appealing and environmentally friendly pathway. According to Gaudiosi and Bori (2010), the total wind energy production (offshore and onshore) could cover $10 \%$ of electricity demand of the Mediterranean countries by 2030 . On the other hand, the development of OWFs alongside other offshore (and coastal) human activities and the imperative need for the conservation of marine habitats seem to be, at first sight, heterogeneous (and often conflicting) aspects. In this regard, it is not straightforward or evident how to harmonize these aspects into a single holistic framework. The relevant arguments that have been raised concerning the impacts of OWFs on the local biotic and abiotic elements (EEA, 2009) necessitate the synthesis of these seemingly opposing aspects into a single holistic framework, where networks of marine protected areas (MPAs) will form the most important marine environmental conservation and protection units.

The EU-funded coordinated project "Towards COast to COast NETworks of Marine Protected Areas (from the shore to the high and deep sea), coupled with sea-based wind energy potential" (CoCoNet) is focused inter alia on the fulfilment of the synthesis of a holistic framework related to the protection and connection of the ecologically important areas in the Mediterranean and Black seas along with the exploitation of the climate-friendly offshore wind power (see also http://www.coconet-fp7.eu/). The CoCoNet project aims firstly to identify interconnected MPA networks within the Mediterranean and Black seas at the local, regional, and basin scale. According to Article 13 of the Marine Strategy Framework Directive, coherent, representative, and interconnected networks of MPAs should represent an integrated system of multiple protected areas designed to conserve regional biodiversity and ecosystem function. In this respect, the approaches considered for the evaluation of the degree of connectivity at the spatial scale are currents, propagules, beta diversity analysis on communities, and genetic diversity. The second main aim of the CoCoNet project is linked to the exploitation of OWE and deals with the integration of geotechnical, socioeconomic, and environmental aspects into a geospatial tool in order to evaluate the feasibility of the installation of OWFs in the examined basins. The identification of the "overall" favourable OWF locations is important in order to secure the financial viability and sustainability of the offshore project, as well as to minimize the negative impacts and maximize the positive effects of OWF installations in the marine environment as a whole. The major outputs from the CoCoNet project are (i) a set of guidelines for the design, management, and monitoring of networks of MPAs and the sustainable development of OWE along with marine conservation goals, and (ii) the Smart Wind Chart (SWC).

Aiming our attention at the second major output, SWC represents a robust and unbiased favourable site identification approach that should be implemented for the integra- tion of all the available information in order to illustrate potential sites for deploying offshore wind installations and to join the networks of MPAs. The visualizing aiding tool for this approach is based on Geographic Information System (GIS) environment. During recent years, due to its flexibility and available features, this spatial analysis tool has been extensively used by renewable energy developers in the context of multi-criteria decision analysis for OWF site selection procedure (see, for example, Atici et al., 2015). Moreover, there are recent studies evaluating OWE development through GIS tools, but only at a national level; for instance, there are assessment studies for Denmark (Möller et al., 2012), Greece (Vagiona and Karanikolas, 2012), Portugal (Costa et al., 2006), and the UK (Cavazzi and Dutton, 2016). Although there are numerous studies proposing multicriteria approaches for wind farm siting (mainly onshore), an integrated approach combining the aforementioned viewpoints with evaluation procedures is still missing for offshore wind applications with reference to an extended spatial scale, such as a large basin.

In this work, the procedure for the implementation of the SWC is presented and applied in the Mediterranean Sea (MS), focused on the corresponding pilot area located in the northern Ionian Sea, in order to formalize the route leading to the identification of favourable zones for OWF development. The comparability of potential locations for developing offshore wind projects is based on quantifiable multi-parameter technical criteria, which are considered of most importance in the OWE industry, combined with environmental restrictions.

The structure of this work is the following: in Sect. 2, the methodology developed in the context of the SWC analysis is presented in more detail. In Sect. 3, the input data, including technical and environmental factors, and the pilot study area in the MS are described at length, and the results obtained after the implementation of the SWC are presented in the subsequent section. In Sect. 5, there is a discussion with reference to some important aspects related to potential misinterpretations of the SWC results and some generic knowledge/information gaps that were encountered at the basin scale. In the last section, some concluding remarks and suggestions are provided for further research.

\section{Methodology for the development of the Smart Wind Chart}

A first step towards the development of a structured methodology, from which optimal OWF sites are determined, is the identification of the main key actors that are involved in the development of OWE projects and are characterized by different, and often contradictory, priorities and requirements. Some of the included key actors include government bodies, policy makers, financing mechanisms, scientists, local communities, NGOs, and wind industry. Seen in this con- 
Table 1. Ranking score and corresponding weightings of potential "go" areas.

\begin{tabular}{|c|c|c|c|c|c|c|}
\hline & $\begin{array}{l}\text { Offshore wind } \\
\text { speed ( } 10 \mathrm{~m} \text { a.s.l.) }\end{array}$ & $\begin{array}{l}\text { Water } \\
\text { depth }\end{array}$ & $\begin{array}{l}\text { Distance } \\
\text { from shore }\end{array}$ & $\begin{array}{l}\text { Proximity to very } \\
\text { large or large ports }\end{array}$ & $\begin{array}{l}\text { Electrical grid } \\
\text { infrastructure }\end{array}$ & $\begin{array}{l}\text { Bottom } \\
\text { sediments }\end{array}$ \\
\hline $\begin{array}{l}\text { Categorization } \\
\text { (rank) }\end{array}$ & $\begin{array}{l}>6.9 \mathrm{~m} \mathrm{~s}^{-1}(5) \\
6.3-6.9 \mathrm{~m} \mathrm{~s}^{-1}(4) \\
5.7-6.3 \mathrm{~m} \mathrm{~s}^{-1}(3) \\
4.9-5.7 \mathrm{~m} \mathrm{~s}^{-1}(2) \\
4.1-4.9 \mathrm{~m} \mathrm{~s}^{-1}(1)\end{array}$ & $\begin{array}{l}10-40 \mathrm{~m} \mathrm{(5)} \\
- \\
70-200 \mathrm{~m} \mathrm{(3)} \\
- \\
40-70 \mathrm{~m} \mathrm{(1)}\end{array}$ & $\begin{array}{l}10-20 \mathrm{~km}(5) \\
5-10 \mathrm{~km}(4) \\
20-100 \mathrm{~km}(3) \\
0-5 \mathrm{~km}(2) \\
>100 \mathrm{~km}(1)\end{array}$ & $\begin{array}{l}0-100 \mathrm{~km} \mathrm{(5)} \\
100-200 \mathrm{~km}(4) \\
200-300 \mathrm{~km} \mathrm{(3)} \\
300-500 \mathrm{~km}(2) \\
>500 \mathrm{~km} \mathrm{(1)}\end{array}$ & $\begin{array}{l}>400 \mathrm{kV} \mathrm{(5)} \\
225-400 \mathrm{kV}(4) \\
36-225 \mathrm{kV}(3) \\
<36 \mathrm{kV} \mathrm{(2)} \\
\text { Distribution grid (1) }\end{array}$ & $\begin{array}{l}\text { Sand (5) } \\
- \\
\text { Mud (3) } \\
- \\
\text { Rock (1) }\end{array}$ \\
\hline Weighting (\%) & 35 & 25 & 15 & 5 & 15 & 5 \\
\hline
\end{tabular}

text, a holistic approach for OWF development requires the rational interweaving of geotechnical/engineering, socioeconomic, and environmental aspects. The development of the SWC moves towards this direction.

SWC is a flexible tool for the comparison and evaluation of the potential OWF locations according to some quantifiable multi-parameter eligibility criteria. However, the locations evaluated through this tool should not be considered as direct suggestions for future OWF development, but merely as favourable candidate areas that deserve further in-depth assessment in the context of detailed feasibility studies. Consequently, the SWC should be regarded as a marine planning tool rather than a decision-making platform.

There are two major steps for the implementation of the SWC: (i) preparatory actions and (ii) processing phase (see also Fig. 1). Preparatory actions include the assessment of the most important quantifiable factors (technical criteria), the factor rating table, and the identification of "no-go/restricted" areas, i.e. areas that are either excluded from further consideration or restricted under specific conditions, mainly due to environmental considerations. The primary technical factors consist of mean annual wind speed and bottom depth whilst the additional factors that were considered include distance to shore, proximity to ports, electrical grid infrastructure, and type of bottom sediments. These factors are categorized in rating tables, and rankings from 1 (least feasible) to 5 (most feasible) are provided for each category. Then, each factor is assigned a weight corresponding to its relative importance on the feasibility of an OWF development. Thus, the overall score for each location is a combination between the factor rating table and the relative weights assigned to each factor (see Table 1). A simple linearly weighted methodology was adopted in order to keep the methodology as straightforward as possible and be easily adoptable and flexible according to the different demands and requirements of the involved key actors. Moreover, future alteration of costs, diversity of local conditions, and any progress in offshore wind technology can be easily integrated in the developed methodology.

In this approach, the exclusion/restriction of an area is primarily based on environmental restrictions, namely national protected sites/MPAs and Natura 2000 sites, areas characterized by meadows of the seagrass Posidonia oceanica, fields of the algae Phyllophora crispa, biogenic habitats such as coralligenous, marl, and deep sea coral formations. Let us note that national protected areas/MPAs and Natura 2000 sites may belong to either restricted or no-go areas; they can be definitively characterized as no-go areas after detailed in situ assessment. On the other hand, areas where the rest of the environmental features are met are characterized as no-go areas; the sensitivity and the vital role (at biological/ecological level) of such features in maintaining the marine coastal equilibrium and preserving marine biodiversity over the long term impose the need to prohibit any (harmful) human marine activity in the corresponding areas. For example, the Mediterranean endemic seagrass species Posidonia oceanica is considered among the natural habitats requiring conservation under the EU's Habitats and Water Framework Directive, since it is among the few representatives of biological quality elements in the MS waters due to its recognized ecological indicator possibilities (Lopez y Royo et al., 2011), while Phyllophora beds supply benthic primary production and water oxygenation in the circalittoral zone, and provide breeding and feeding grounds, and nursery for diverse invertebrate and fish species (Salomidi et al., 2012). Other restrictions may be attributed to marine and maritime uses (e.g. military exercise areas, areas of fisheries and aquaculture, shipping lanes, oil and gas extraction areas). However, such considerations are the main object of marine spatial planning and refer to site-specific studies concerning OWF development (see Sect. 5 for more details).

In the processing phase, the two most important (technical) parameters have been firstly taken into consideration for the primary identification of the site suitability: mean annual wind speed and bottom depth. The former is evaluated for the grid points that are not under any environmental restriction, and then the corresponding value for the latter one is extracted. Regarding mean annual wind speed, the lowest threshold was set to $4.1 \mathrm{~m} \mathrm{~s}^{-1}$ at $10 \mathrm{~m}$ a.s.l. (meters above sea level). This rather low limit is justifiable since Eta-SKIRON underestimates (sometimes significantly) wind speed with respect to satellite data and buoy measurements (see Soukissian and Papadopoulos, 2015). Regarding bottom depth, three different water depth ranges were considered: (i) 0-40 m ("shallow waters"), (ii) 40-70 m ("intermediate" 
Grid analysis and generation of GIS layers

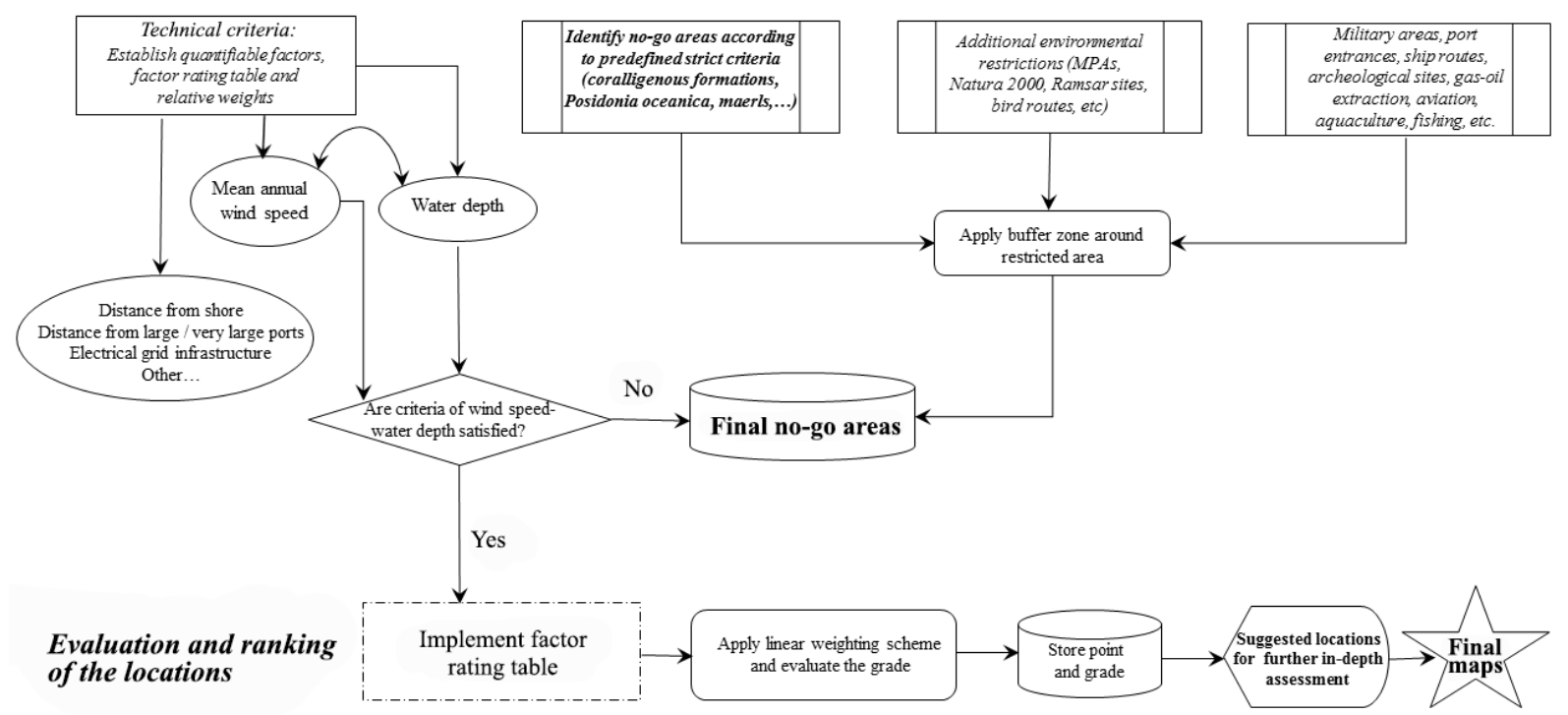

Figure 1. Flow chart for the development of the SWC.

or "transitional waters"), and (iii) 70-200 m ("deep waters"). Shallow and intermediate water depths refer to monopile, gravity-based, tripod, jacket, and tripile supporting structure, while deep waters refer to floating wind turbines technologies. Although fixed foundations are to date dominant in the offshore wind market, floating structures seem to be a viable alternative solution, especially for the Mediterranean waters, provided that the relevant floating technology reach the desired maturity level in the coming years.

If the combination of wind speed and bottom depth satisfies the adopted thresholds (i.e. mean annual wind speeds greater than $4.1 \mathrm{~m} \mathrm{~s}^{-1}$ at $10 \mathrm{~m}$ a.s.l. height and water depths smaller than $200 \mathrm{~m}$ ), then the point (area) is characterized as "potentially go" area and is graded according to the examined factors and the relative weights, so that the final rankings of the locations are derived. At the end of the analysis, the potentially suitable sites worth being further assessed for OWF development are identified with the highest overall scores characterizing the most favourable sites. Let us note that any preliminary national spatial planning for OWFs is also included in the analysis. Such plans exist for France, Greece, Italy, and Spain; however, some of these plans are currently under revision.

\section{Data and study area}

\subsection{Data sources}

Wind data can be obtained from various sources that may use different measuring principles, devices, and configurations; these variations contribute to uncertainties in the longterm wind speed (and resource) assessment and should be properly considered (Soukissian and Papadopoulos, 2015). In this work, the results obtained from the Eta-SKIRON model (Papadopoulos et al., 2011) were used since they have the finest available spatial $\left(1 / 10^{\circ} \times 1 / 10^{\circ}\right)$ and temporal $(3 \mathrm{~h})$ resolution. The simulation period is 15 years (1995-2009) with reference height at $10 \mathrm{~m}$ a.s.l., and the initial conditions were provided by the ERA- 40 reanalysis data and the operational analyses of the European Centre for Medium-Range Weather Forecasts (ECMWF), through the Hellenic National Meteorological Service. The Eta-SKIRON model is based on the Eta-NCEP (National Centre for Environmental Prediction) model and was developed for operational purposes. Its unique capabilities make it appropriate for mesoscale simulations in regions with varying geographic characteristics.

The bathymetric information was obtained by the EMODnet Bathymetry portal (generated in February 2015) with grid size resolution $1 / 8 \times 1 / 8 \mathrm{arcmin}$ (see also http:// www.emodnet-hydrography.eu/). This bathymetry has been produced from bathymetric survey data and aggregated bathymetry data sets collated from public and private organizations.

Distance from the shore is highly connected with socioeconomic aspects; a short distance from the shore minimizes all the costs related to the technical infrastructure, installation and maintenance activities (i.e. capital and operating expenditures), but on the other hand it maximizes visual disturbance. The coastline from EEA was used for delimiting the specified distances from the shore (Table 1).

Similarly, regarding proximity to ports, as distances from ports shorten, the accessibility to the offshore wind project area is faster and more economical. These distances were derived from the World Port Index Database of the National 

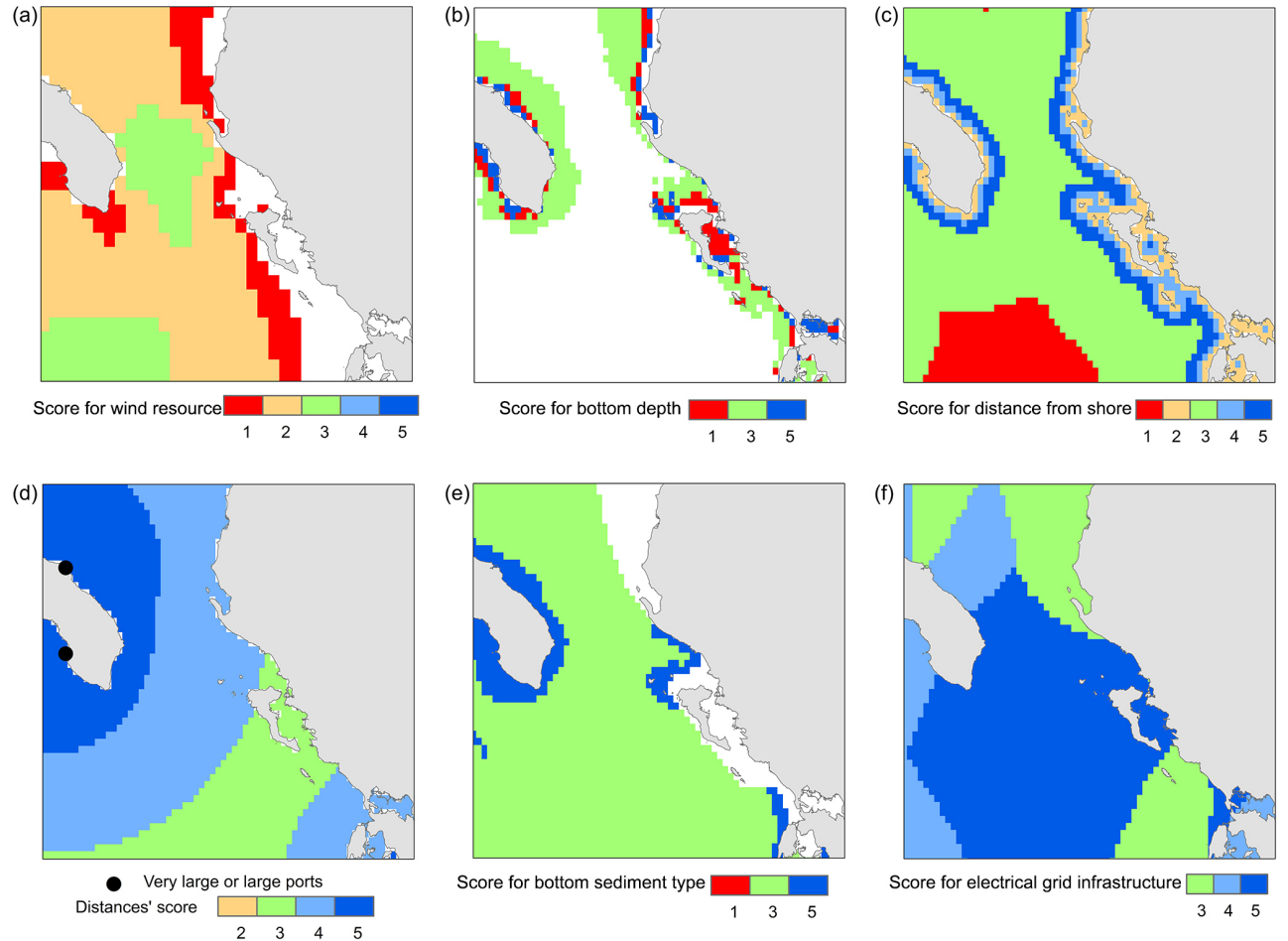

Figure 2. Results from the SWC as regards technical criteria in the Mediterranean pilot area: score for wind resource (a), score for bottom depth (b), score for distance from the shore (c), score for proximity to ports (d), score for bottom sediment type (e), and score for electrical grid infrastructure (f).

Geospatial Intelligence Agency (WPI 2015 pub. 150, http: //msi.nga.mil/NGAPortal/MSI.portal). The ports included in the analysis are those whose controlling depth of the principal or deepest channel or the greatest depth alongside the wharf/pier is over $10 \mathrm{~m}$.

Regarding bottom sediments, the existence of cobbles, boulders, dense or soft sand, etc., affects the foundation design and cable laying. The type of bottom sediments was derived via digitization of the Unconsolidated Bottom Surface Sediments of the International Bathymetric Chart of the Mediterranean (IBCM) of the Intergovernmental Oceanographic Commission, and the scale of the corresponding map is $1: 1000000$.

The assessment of the existing electrical grid infrastructure was based on the 2014 ENTSO-E Interconnected Network Grid Maps (see www.entsoe.eu). ENTSO-E's Interconnected Grid Map is one of the publications of this association. It displays the electricity transmission grid as of $31 \mathrm{De}-$ cember 2014, and the scale of the map is $1: 4000000$.

The data of all the environmental variables were derived from the "Mediterranean Sensitive Habitat" (MEDISEH) project (see http://mareaproject.net/). These data were partially based on (i) revision of historical and current data from the compilation of published and unpublished information, and (ii) habitat suitability modelling that was applied to fill spatial information gaps on the distribution of such species by predicting the locations that habitats are likely to be suitable for species to live (Giannoulaki et al., 2013). For the pilot site, the model results were based on a large number of personal observations that were collected related to the occurrence of Posidonia oceanica, and some point data sources for coralligenous and marl beds.

\subsection{Description of study area}

The Diapontia Islands, an island complex opposite to the north-western coasts of Corfu, Greece, were selected as a pilot area for OWF development in the context of the CoCoNet project and were used to develop the rationale of SWC. The main reason for this selection is that the Greek government (by the Ministry of Environment, Energy and Climate Change in 2011) has already preselected the area for potential OWF development; from this point of view, it comprises a realistic case to be studied in depth. The relevant activities are scheduled to take place in various phases. In the first phase (which is at the concept/early planning status), the foreseen capacity is $15 \mathrm{MW}$ (three turbines each of $5 \mathrm{MW}$ nominal power) (see www.4coffshore.com).

On the other hand, the selected area encompasses features that are very representative of the coastal areas of the MS. Specifically, Diapontia Islands do not belong to the few top-ranked areas according to the wind resource availability 
(a)

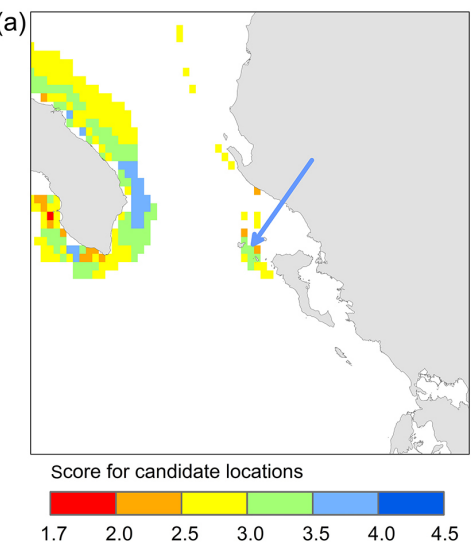

(b)

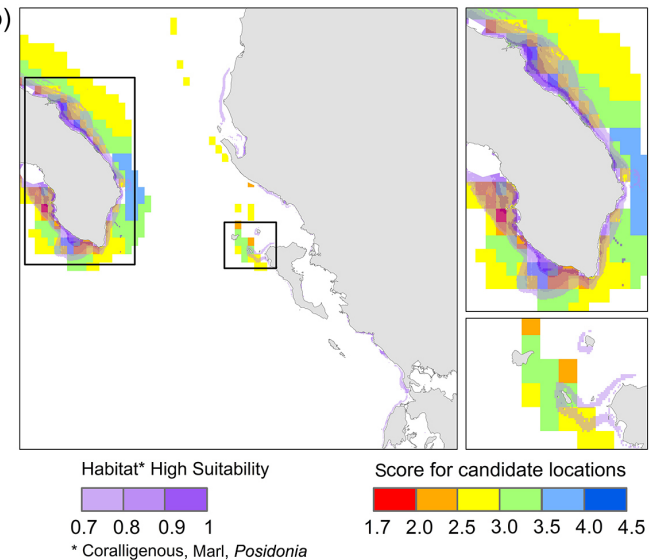

Figure 3. Overall score for candidate locations for OWF development in the Mediterranean pilot area (a). Overall score combined with habitats (coralligenous formations, marls, Posidonia oceanica meadows) with high suitability in the Mediterranean pilot area (b).

while the wind and wave climate is rather mild. Moreover, a Natura 2000 site is designated in the proximity of the examined area and, in the meantime, the wider area is well developed as regards tourism and fisheries, which comprise two of the most characteristic marine uses in the MS.

\section{Results}

Based on the methodology discussed in Sect. 2, the results for each examined parameter are firstly presented and described separately (Fig. 2a-f) for the pilot site in order to identify step by step favourable candidate locations for offshore wind exploitation, and then the final output is depicted (Fig. 3a) after combining the data sets via raster calculation method.

Specifically, the score as regards wind resource (Fig. 2a) is marginally appropriate (rank 1) for potential OWF development in the pilot site, while bottom depth (Fig. 2b) is ideal and characterized by the best score (rank 5). The score for distance from the shore (Fig. 2c) ranges between 2 and 4 in the wider examined pilot area while the corresponding score for distance from ports (Fig. 2d) is right before the top (rank 4). Finally, from Fig. 2e and f, it is evident that the bottom sediment type and the existing electrical grid infrastructure, respectively, are optimum for potential OWF development in this site (rank 5), since the existent electrical grid infrastructure seems to be adequate and the sea bed composition is sandy. The final scores as regards the examined technical parameters are depicted in Fig. 3a. The total technical suitability rating for the Othonoi site (one of the main islands of Diapontia Islands), shown with an arrow in the same figure, is between 3.0 and 3.5. Let us reiterate that the overall score of the candidate areas for OWF development are obtained by applying a linear weighting scheme. Comparing this rank to the other locations and according to the overall score scale, this area is considered "fair" as regards its favourability for OWF development.
Finally, superimposing the technical criteria with available data based on environmentally sensitive areas, we obtain the synthetic Fig. 3b. According to the obtained results, the likelihood for formation of Posidonia oceanica meadows, coralligenous formations, and marls is not very high in the study area based on the simulation models. However, in-depth assessment of these environmental aspects along with submarine archaeological findings and migratory bird routes are some of the main objectives of environmental impact assessment studies and require a systematic survey of any candidate area for OWF development. In conclusion, with a total relative score 3.0-3.5, it seems that Othonoi is a good choice in the northern part of the Ionian Sea. In this respect, the site has been rightly pre-selected from the Greek government as a site for potential OWF development.

\section{Discussion}

For the sake of completeness of this work, in this section some problems encountered during the development and implementation of the SWC are presented, along with some relevant remarks as regards the interpretation of the SWC results. The majority of the problems are related to the main knowledge/information gaps that were identified during the background data collection and assessment.

The first issue refers to data availability and quality. Specifically, regarding wind data the following (interconnected) issues are of most importance:

i. There is lack of high-resolution data at the basin scale. High-resolution wind data (usually obtained from numerical models or gridded satellite products) are necessary for the accurate estimation of the wind energy characteristics in nearshore/coastal areas (where the coastal morphology plays an important role in wind patterns) and the more detailed estimation of the relevant uncertainties. 
ii. There is lack of offshore measurements at the usual operational turbine hub heights (i.e. within the range of $70-110 \mathrm{~m}$ a.s.l.). Measured wind data of the wind profile are necessary in order to estimate reliably the actual wind energy characteristics at hub heights. The wind profile can be accurately deduced only by utilizing measured wind data at various heights a.s.l., which, currently, may be obtained either by meteorological masts or lidar (light detection and ranging) measurements. Furthermore, such measurements are also necessary in order to evaluate less reliable data sources such as numerical models or satellite products. However, there is lack of lidar measurements in the Mediterranean and Black seas, and the installation, operation and maintenance of meteorological masts are expensive procedures, especially for offshore locations.

The data quality issue is also associated with the inherent uncertainties of wind speed data and, consequently, wind power density estimates, i.e. the most determinative parameter for SWC analysis. Before the implementation of the SWC, four different wind data sources (measurements from two buoy networks, satellite products, and results from two numerical weather prediction models) were assessed for the MS in order to be statistically analysed and evaluated. The analysis revealed that there were statistically significant deviations between the examined data sources. However, as it was recommended by Soukissian and Papadopoulos (2015), calibration schemes can be efficient in local spatial scales while it is very risky to apply them in large spatial scales, such as the examined basins. Eventually, the most representative data source with the highest spatiotemporal resolution was adopted. On the other hand, such uncertainties necessarily should be taken into consideration when site-specific studies are made for potential OWF development.

More detailed spatial information is vital regarding also marine environmental data. The more accurate mapping of important habitats at the critical bottom depths for OWF development, such as meadows of Posidonia oceanica, fields of Phyllophora crispa, coralligenous, and deep-water white coral formations, provide necessary background information for efficient OWF planning in wide areas. Moreover, bird migration routes over the same areas should be defined as accurately as possible and relevant quantitative information should be available.

However, the most important information gap seems to be the lack of a basin-wide marine spatial planning. Some European Mediterranean countries have coarse preliminary spatial plans and very few detailed plans at regional level tailormade for OWE projects (e.g. at the Gulf of Lions in France). In addition, since OWF installations are expected to affect coastal zone activities, integrated coastal zone management (combined with relevant information on the socio-economic status of the area) is also required as a necessary complementary tool for marine spatial planning. In this regard, socio- economic aspects could be included in future SWC applications, even in extended sea areas.

Another aspect to call attention to, especially when interpreting the SWC results, is related to the appropriate consideration of the involved spatial scales. The spatial extent of the examined basin, the heterogeneity of the considered data sets, and the data spatial scales do not allow a detailed (in the spatial domain) and in-depth (as regards the involved parameters) analysis, let alone the lack of data, especially with respect to socio-economic aspects. Specifically, the geographical extent of the MS is of the order of several hundreds of kilometres, which assigns the magnitude of the spatial scale, and, in turn, the data involved. The next most important spatial scale is connected to the spatial resolution of wind data. The resolution of the numerical model we have used is roughly of the order of $10 \mathrm{~km} \times 10 \mathrm{~km}$ (see also Sect. 3.1). Here, the underlying assumption is that the wind information contained in the area corresponding to the model grid point (i.e. $100 \mathrm{~km}^{2}$ ) is homogeneous and representative of the entire "pixel". Although this assumption can be valid for morphologically homogeneous sea areas (e.g. offshore areas), there are cases in which it may be incorrect (e.g. for coastal areas). Moreover, the spatial resolution of bathymetric data is, in principle, not compatible with the wind data resolution, since it is roughly of the order of $200 \mathrm{~m}$. Let us also mention that a large part of bathymetric data have been produced by interpolation methods and thus cannot be considered as fully accurate. In this respect, outputs of the SWC can only provide some preliminary suggestions for potential OWF development, mainly through indicative zones, in the examined basin. Since this spatial scale may lead to misjudgements as regards the development of offshore wind projects, a detailed local assessment of technical, socio-economic, and environmental features at the finest possible spatial scale is required for localized cases in order to reach final decisions and form strategies.

\section{Conclusions}

The identification of potential zones for offshore wind farm development is a very delicate procedure and should be based on sufficient and high-quality data regarding both biotic and abiotic elements of the marine environment. An integrated and interdisciplinary approach has been adopted integrating technical, and environmental criteria and data related to the offshore wind energy exploitation. The integration is implemented through a robust tool - the so-called Smart Wind Chart, aiming to maintain and secure the sustainable blue growth in the Mediterranean and Black seas through the support of offshore wind energy projects and marine habitat conservation. The application of the Smart Wind Chart in the northern Ionian Sea provided one of the most favourable candidate areas for offshore wind farm development in this part of the Hellenic seas, which, in this case, coincides with 
the suggestion of the Greek government. On the other hand, some knowledge and information gaps were evident during the implementation of the Smart Wind Chart while some additional aspects, related to the uncertainties of the wind data involved and the involved spatial scale of the data, were explicated in order to prevent misinterpretations of the outputs.

It is, however, important to note that the results obtained from the Smart Wind Chart cannot replace an in-depth environmental and socio-economic impact assessment study, which includes the corresponding mapping and monitoring of any candidate area and, in general, more detailed analysis with high-resolution data. Considering the future introduction of offshore wind farm installations in the Mediterranean Sea, the potential impacts should be closely linked to the environmental and ecological processes. Standardized monitoring protocols and a clear guidance on the assumptions and requirements of monitoring programmes are necessary, in agreement with the scientific community and regulatory bodies (Franco et al., 2015).

Acknowledgements. The research leading to these results has received funding from the European Community's Seventh Framework Programme (FP7/2007-2013) under grant agreement no. 287844 for the project "Towards COast to Coast NETworks of marine protected areas (from the shore to the high and deep sea), coupled with sea-based wind energy potential".

Edited by: D. Montesinos

Reviewed by: two anonymous referees

\section{References}

Atici, K. B., Simsek, A. B., Ulucan, A., and Tosun, M. U.: A GIS-based Multiple Criteria Decision Analysis approach for wind power plant site selection, Utilities Policy, 37, 86-96, doi:10.1016/j.jup.2015.06.001, 2015.

Cavazzi, S. and Dutton, A. G.: An Offshore Wind Energy Geographic Information System (OWE-GIS) for assessment of the UK's offshore wind energy potential, Part 1, Renew. Energ., 87, 212-228, doi:10.1016/j.renene.2015.09.021, 2016.

Costa, P., Simoes, T., and Estanquero, A.: Assessment of Sustainable Offshore Wind Potential in Portugal, in: Proceedings of European Wind Energy Conference and Exhibition (EWEC), Athens, Greece, 27 February-2 March 2006, 3, 2006.
European Environmental Agency: Europe's onshore and offshore wind energy potential. An assessment of environmental and economic constraints, Technical report No 6, 90 pp., 2009.

Franco, A., Quintino, V., and Elliott M.: Benthic monitoring and sampling design and effort to detect spatial changes: A case study using data from offshore wind farm sites, Ecol. Indicators, 57, 298-304, doi:10.1016/j.ecolind.2015.04.040, 2015.

Gaudiosi, G. and Borri, C.: Offshore wind energy in the Mediterranean countries, Revue des Energies Renouvelables SMEE'10 Bou Ismail Tipaza, 173-188, 2010.

Giannoulaki, M., Belluscio, A., Colloca, F., Fraschetti, S., Scardi, M., Smith, C., Panayotidis, P., Valavanis, V., and Spedicato, M. T. (Eds.): Mediterranean Sensitive Habitats (MEDISEH), final project report, DG MARE Specific Contract SI2.600741, Hellenic Centre for Marine Research, 557 pp., 2013.

Lopez y Royo, C., Pergent, G., Alcoverro, T., Buia, M. C., Casazza, G., Martínez-Crego, B., Pérez, M., Silvestre, F., and Romero, J.: The seagrass Posidonia oceanica as indicator of coastal water quality: Experimental intercalibration of classification systems, Ecol. Indicators, 11, 557-563, doi:1016/j.ecolind.2010.07.012, 2011.

Möller, B., Hong, L., Lonsing, R., and Hvelplund, F.: Evaluation of offshore wind resources by scale of development, Energy, 48, 314-322, doi:10.1016/j.energy.2012.01.029, 2012.

Papadopoulos, A., Korres, G., Katsafados, P., Ballas, D., Perivoliotis, L., and Nittis, K.: Dynamic downscaling of the ERA-40 data using a mesoscale meteorological model, Medit. Mar. Sci., 12, 183-198, doi:10.12681/mms.59, 2011.

Salomidi, M., Katsanevakis, S., Borja, A., Braeckman, U., Damalas, D., Galparsoro, I., Mifsud, R., Mirto, S., Pascual, M., Pipitone, C., Rabaut, M., Todorova, V., Vassilopoulou, V., and Vega Fernandez, T.: Assessment of goods and services, vulnerability, and conservation status of European seabed biotopes: a stepping stone towards ecosystem-based marine spatial management, Medit. Mar. Sci., 13, 49-88, doi:10.12681/mms.23, 2012.

Soukissian, T. H. and Papadopoulos, A.: Effects of different wind data sources in offshore wind power assessment, Renew. Energ., 77, 101-114, doi:10.1016/j.renene.2014.12.009, 2015.

Vagiona, D. G. and Karanikolas, N. M.: A multicriteria approach to evaluate offshore wind farms sitting in Greece. Glob NEST J, 14, 235-243, 2012. 